\title{
Nonlinear Finite Element Analysis to Evaluate Lateral Torsional Buckling Moment of Elliptical Cellular Steel Beams
}

\author{
Kitjapat Phuvoravan ${ }^{\mathrm{a}}$ and Phattaraphong Ponsorn ${ }^{\mathrm{b}, *}$ \\ Department of Civil Engineering, Faculty of Engineering, Kasetsart University, Bangkok 10900, Thailand \\ E-mail: akitjapat@hotmail.com, bm.phatphong@hotmail.com (Corresponding author)
}

\begin{abstract}
In evaluation the lateral torsional buckling moment of Elliptical Cellular beams, it cannot be accurately calculated using a simple model because the sectional properties of the Elliptical Cellular beam are not constant along the beam length. Consideration of sectional properties at the web-post section will certainly lead to unconservative results, while consideration of sectional properties at the web-opening section is also unreal and yield conservative design. Therefore, the main objective of this paper is to present the guideline to evaluate the lateral torsional buckling moment capacity of Elliptical Cellular beam for conservative and more precise results. The study has been performed throughout finite element analysis in both elastic and inelastic buckling behavior subjected to equal beam-end moments. More than 15 sections, 120 of beam models were simulated and analyzed with verified finite element modelling by using shell elements. The results of this study show that calculation the lateral torsional buckling moment of Elliptical Cellular beam with the original equation given in AISC standard using sectional properties at the web-post section gives unsafe results with approximately 5\% error in elastic range and up to $20 \%$ error in inelastic and plastic range. Nonetheless, evaluation the lateral torsional buckling moment by using the proposed reduction factor has yielded the conservative results, yet more precision, more economic and less distribution of the results than the evaluation using sectional properties at the web-opening section.
\end{abstract}

Keywords: Elliptical cellular beam, lateral torsional buckling, finite element analysis.

ENGINEERING JOURNAL Volume 21 Issue 1

Received 14 February 2016

Accepted 19 May 2016

Published 31 January 2017

Online at http://www.engj.org/

DOI:10.4186/ej.2017.21.1.93 


\section{Introduction}

Cellular beam is a circular web-openings steel beam fabricated by cutting the web of the standard hot-rolled wide flange section with certain pattern into two pieces and then reassembling the two halves again by welding. As a result, the beam depth is increased but leaving the circular holes at the beam web. The main engineering advantage is that the stiffness and the strength can be increased with the same amount of material. Another web-openings beam is also so-called by the configuration of opening shape, such as Castellated beam for hexagonal web-openings shape, Angelina beam for sinusoidal web-openings shape, and presented in this paper, Elliptical Cellular beam for elliptical web-openings shape. This modern Elliptical Cellular beam has the elliptical web-opening configuration that is developed base on the typical hexagonal shape from design of Castellated beam by BS 5950 and BS 449 standard [1] (see Fig. 1). The web-opening shape has to use technology for cutting and welding in elliptical curves pattern, but little more effective advantages than Castellated beam and Cellular beam as previous research [2-7] that can be drawn as followings:

- The elliptical web-opening shape has less critical opening length than circular web-opening shape, which affect to demote occurring of Vierendeel mechanism failure.

- The curvature of elliptical opening effectively contribute to reduce stress concentration at corners of hexagonal opening shape.

- The curvature of elliptical opening that take place to corner of hexagonal opening has reduce tearing and fracture mechanism.

- The Elliptical Cellular beam developed base on typical hexagonal web-opening shape has fix on dimension ratio, suitable for practical application.
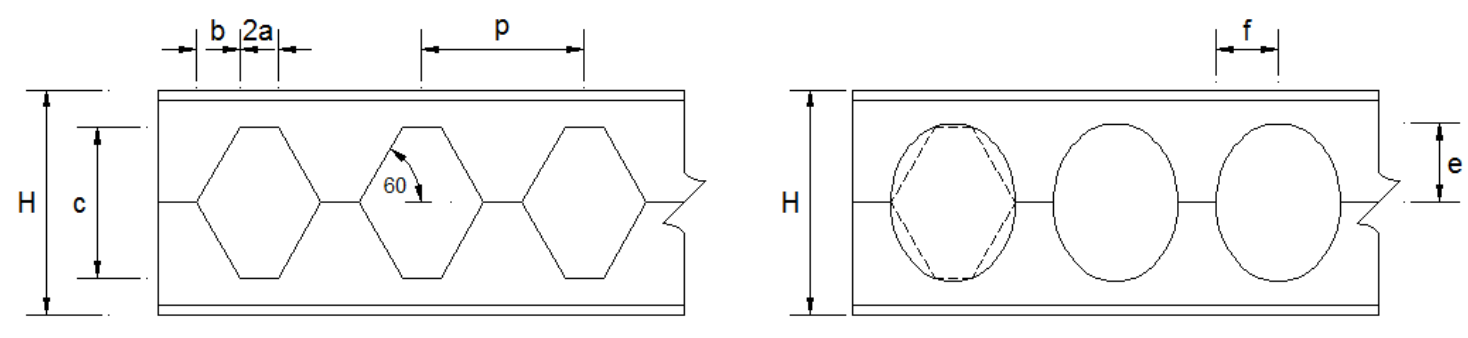

Fig. 1. The configuration of elliptical web-opening developed base on typical hexagonal web-opening shape from the design of Castellated beam with BS 5950 and BS 449 standard [18].

There are many researches on behavior and failure modes of web opening beams that the beam length is not long [8-12]. But, in long span length, fabricating original steel beam into Elliptical Cellular beam has a good solution to control the deflection of beam. Subsequently, the beam with long span length will be vulnerable to lateral torsional buckling behavior if no sufficient bracings against lateral displacement of the compression flange or bracings against twist of the cross section. Therefore, to account for the lateral torsional buckling moment of original I-shaped steel beam, general provision of AISC 360-10 [13] specifies the equation to evaluate the lateral torsional buckling moment as Eq. (1) for the range of elastic lateral torsional buckling and Eq. (2) for the range of inelastic lateral torsional buckling. In the equations, $C_{b}$ is the lateral torsional buckling modification factor for nonuniform moment diagrams, $S_{x}$ is the elastic section modulus taken about the x-axis, $M_{p}$ isthe plastic moment, $L_{b}$ is the length between lateral supports, $L_{p}$ is the limiting length between plastic and inelastic behavior, $L_{r}$ is the limiting length between inelastic and elastic behavior, $G$ is the shear modulus of elasticity, and $E$ is the Young's modulus of elasticity.

$$
M_{c r}=C_{b} \frac{\pi}{L_{b}} \sqrt{E I_{y} G J+\left(\frac{\pi E}{L_{b}}\right)^{2} I_{y} C_{w}}
$$




$$
M_{n}=C_{b}\left[M_{p}-\left(M_{p}-0.7 F_{y} S_{x}\right)\left(\frac{L_{b}-L_{p}}{L_{r}-L_{p}}\right)\right] \leq M_{p}
$$

Nevertheless, these two equations are derivedfor original I-shape steel beam with constant sectional properties. Thus, it cannot be used to precisely evaluate the Elliptical Cellular beam since the beam has web-openings that make sectional properties, moment of inertia about minor axis $I_{y}$, torsional rigidity $J$ and warping constant $C_{w}$, vary along the beam length. And the use of sectional properties at the web-opening section to evaluate the lateral torsional buckling moment of the beam is unreal and too conservative. Although there are some previous researches on lateral torsional buckling behavior [14-20] and design [2123] of Cellular and Castellated beam, these researches have not obviously included all the design ranges of the beams and not extended to the elliptical opening shape. So the purpose of this paper is to conduct the parametric study and propose a simplified coefficient function for precisely evaluate the lateral torsional buckling moment of Elliptical Cellular beam in both elastic and inelastic buckling range throughout finite element analysis.

\section{Nonlinear Finite Element Modelling}

To investigate the lateral torsional buckling moment capacity of Elliptical Cellular beams in this study, the nonlinear finite element analysis using the commercial software package, ANSYS ver.R14.5 program [24], has been performed with both geometric and material nonlinearities. The assumptions and definitions are described as followings.

\subsection{Material Properties}

A bi-linear elastic-perfectly plastic stress-strain curve has been adopted to simulate the nonlinear behavior of steel material. The used material parameters are Young's modulus of $2 \times 10^{5} \mathrm{MPa}$, shear modulus of $7.6923 \times 10^{4} \mathrm{MPa}$, tangent modulus of $1 \times 10^{-13} \mathrm{MPa}$, yield stress of $250 \mathrm{MPa}$ and Poisson's ratio of 0.3 . It is worthly noted that the consideration the residual stress of the hot-rolled steel beam and fabricating Elliptical Cellular beam is complicated, yet not essentially found in any literature review, thus, it is not taken into account in the scope of this study.

\subsection{Finite Element Type and Mesh}

A four-node structural shell element (SHELL181) from ANSYS ver.R14.5 library has been used in this nonlinear finite element analysis to investigate the lateral torsional buckling moment. The element has six degrees of freedom at each node, 3 translations in the $x, y$ and $z$ directions and 3 rotations about the $x, y$ and $\mathrm{z}$ axis. The element is suitable for large rotation, large strain nonlinear application and load stiffness effect of distributed pressures. Both full and reduced integration schemes are also supported. The performance of nonlinear buckling finite element convergence shows that the element mesh size of about quarter of flange width (as shown in Fig. 2) is suitable and sufficient to apply in this investigation.

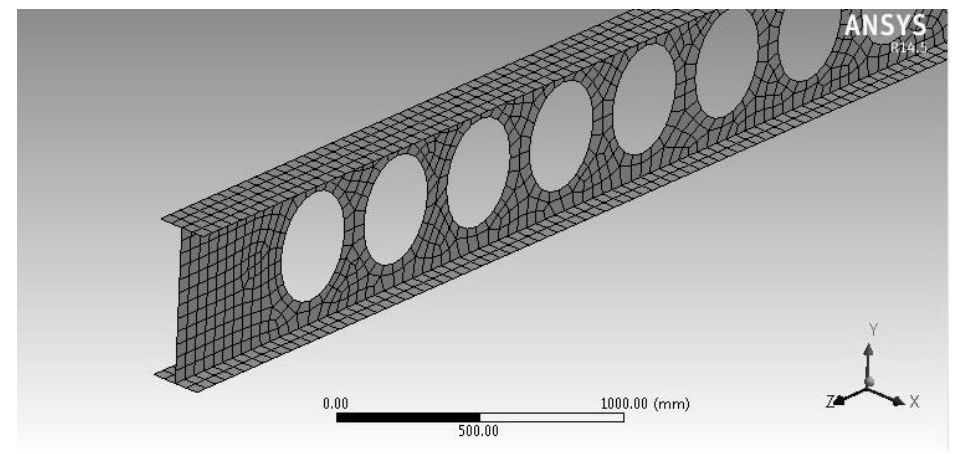

Fig. 2. Shell element mesh size of quarter of flange width (ECB600x200 specimen). 


\subsection{Boundary Conditions and Load Application}

The simple beam with equal end moments has been used in this study. One of the end supports is assigned to be hinge, while another is roller. The rotations about beam's self are restrain at both support, while it is free for in-plane and out-of-plane rotations. Action loads of equal end moments have been obtained as a result by applying the rotation control.

\subsection{Initial Geometric Imperfection}

In reality, all of the general beams are initial geometrical imperfect due to a manufacturing of hot-rolled steel fabrication process, or additional secondary fabrication process to Elliptical Cellular beams. This initial geometric imperfection can be considered in this nonlinear buckling analysis as initial deformation by using ANSYS program [24]. The procedure of analysis is linked in two parts. Firstly, the initial deformation is obtained from linear buckling by using eigenvalue and eigenvector modal analysis. The obtained initial deformation can be multiplied to enlarge magnitude of the deformation. Then, the finite element model with initial deformation will be updated and import to part of nonlinear buckling analysis. Nevertheless, the shape and location of geometric imperfections in reality are varied and hard to discern. Therefore, to judiciously consider the imperfection of Elliptical Cellular beam in this nonlinear buckling analysis, the initial deformation will be set to half-sine lateral torsional buckling mode which is the first mode shape of linear buckling with the magnitude of 0.0005 of the span length (L/2000).

\section{Verification of Nonlinear Finite Element Model}

In order to accurately apply the nonlinear finite element analysis to Elliptical Cellular beam in this study, the verification of finite element model has been performed by finite element convergence and comparing two simulated models with two experimental test results, by J. Nseir [21] and K. D. Tsavdaridis [5]. The model compared with J. Nseir was simulated using HEA 340 Cellular beam with the length of $7500 \mathrm{~mm}$. The material properties are referred with a coupon test result with Young's modulus of 230 GPa and the yield stress of $522 \mathrm{MPa}$. The stress-strain curve of the steel material is modeled as bi-linear elastic-perfectly plastic. The deformation and equivalent stress of the simulated Cellular beam are shown in Fig. 3. Figure 4 shows the result of comparison of load-displacement that represent a good agreement between the experimental test and the nonlinear finite element model. The finite element model shows the ultimate vertical load of $2023 \mathrm{kN}$, which is merely $2.33 \%$ error from the experimental test result.

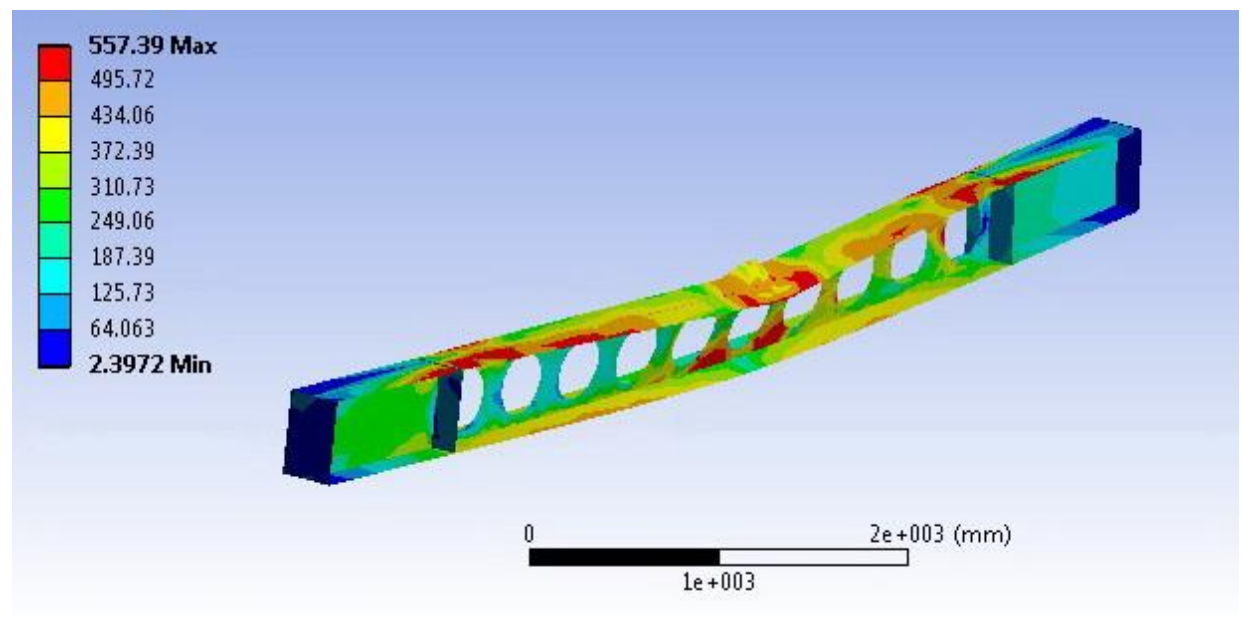

Fig. 3. Equivalent (Von-mises) stress of HEA 340x7500 $\mathrm{mm}$ at the maximum loading. 


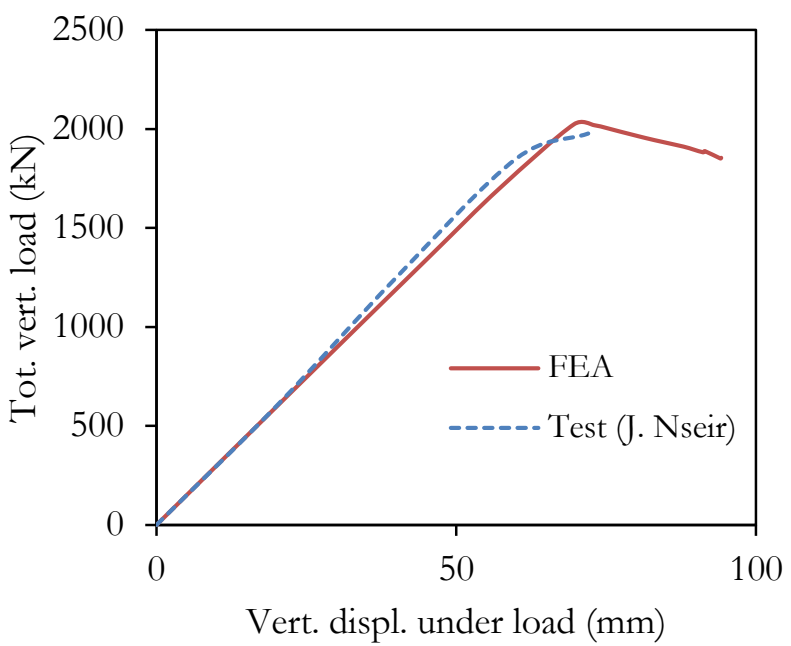

Fig. 4. Comparison of load-deflection of Cellular beam with experimental test [21] (HEA 340x7500 mm).

In the verification comparing with K.D. Tsavdaridis [5], the model was simulated with the specimen B3, simply supported beam with a mid-span concentrated load. This specimen is UB457x152x52 section with vertical elliptical web openings (theta $=10$ and $R=0.25 \mathrm{~d}_{\mathrm{o}}$ ). The beam depth $\mathrm{h}$ of $449.8 \mathrm{~mm}$, the beam width $b$ of $152.4 \mathrm{~mm}$, the flange thickness $t_{f}$ of $10.9 \mathrm{~mm}$, the web thickness $t_{w}$ of $7.6 \mathrm{~mm}$, the $d_{o}$ of $315 \mathrm{~mm}$, the $\mathrm{R}$ of $47.25 \mathrm{~mm}$, the theta of 10 , the critical web post width $\mathrm{S}$ of $63 \mathrm{~mm}$, the stiffeners at both supports of $10.9 \mathrm{~mm}$, the stiffener at mid-span of $20 \mathrm{~mm}$, and the clear span length $\mathrm{L}$ of $1700 \mathrm{~mm}$ are all the dimensions used in analysis. The steel material of S355 grade (tensile coupon test with $\mathrm{f}_{\mathrm{y}}$ of $375.3 \mathrm{MPa}$ and 359.7 MPa, and fult. of 492.7 MPa and 480.9 MPa) is simulated using tri-linear material model. The result of the simulation is shown in Fig. 5 to overall compare the equivalent (Von-mises) stress contour and total deformation at the maximum load. The load-deflection comparison has been shown in Fig. 6 using the results of the vertical deflection at mid-span length (dial gauge 3). The results of the load-deflection graph, the stresses, the deformation and the behavior are in good agreement. The failure mode is web-post distortional buckling at the ultimate load of $437.40 \mathrm{kN}, 415 \mathrm{kN}$ and $426 \mathrm{kN}$ for this simulated model, K.D. Tsavdaridis's experimental test and Tsavdaridis's finite element analysis, respectively.

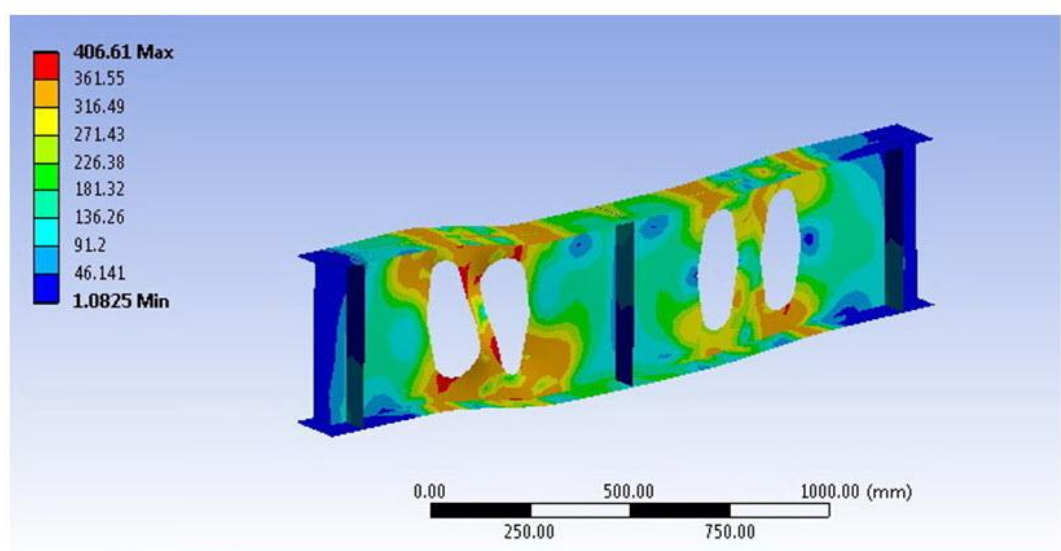

(a)
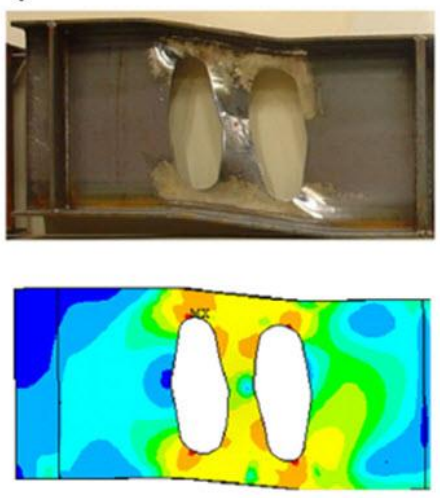

(b)

Fig. 5. Comparison of result in specimen B3: (a) simulated model at equivalent (Von-mises) stress along with deformation at last load, (b) result from K.D. Tsavdaridis [5]. 


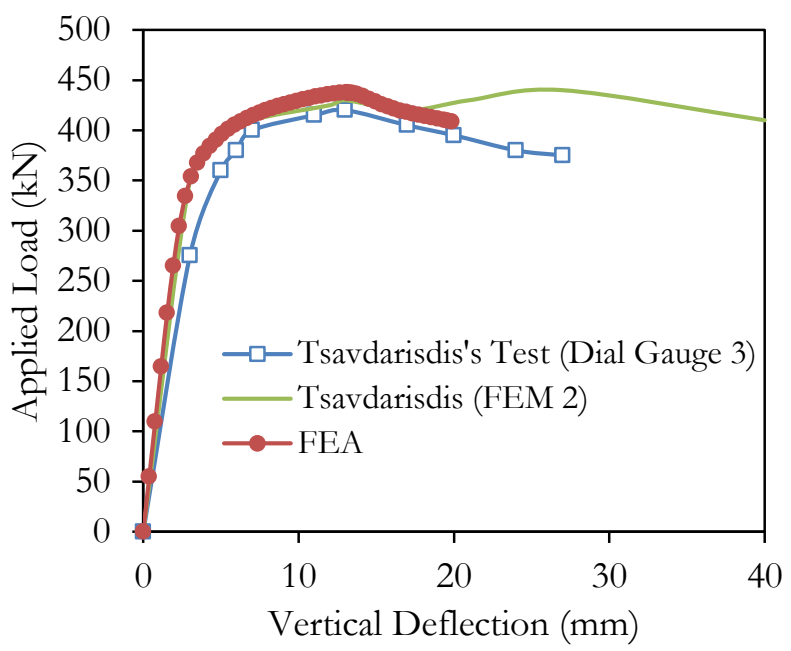

Fig. 6. Verification of finite element analysis with the experimental test of specimen B3 [5].

\section{Parametric Study}

After the finite element modelling has been verified carefully, the nonlinear buckling analysis can properly be applied with several cases of Elliptical Cellular beams (ECB) by parametric study that aim to evaluate the lateral torsional buckling moment capacity and to collect the reference results in order to propose a coefficient function for further use in design purpose. The one hundred and twenty models with fifteen sections of Elliptical Cellular steel beam have been extensively chosen for this parametric study. The length of all beam models are provided in both of the elastic and inelastic buckling behavior range, as well as the slenderness of section were chosen in widely various. The grade of material is S250 (grade of 36). Table 1 shows the details of sections and dimensions of the Elliptical Cellular beam. The terminology is defined as followings; $\mathrm{H}$ is the height of Elliptical Cellular section, $\mathrm{d}$ is the height of the original standard $\mathrm{I}$-beam, $\mathrm{B}_{\mathrm{f}}$ is the width of section, $t_{f}$ is the flange thickness, $t_{w}$ is the web thickness, $e$ is the half-height of the elliptical opening, $f$ is the half-width of the elliptical opening, and $p$ is the pitch length of the opening. The others Castellation dimensions were followed base on the design of castellated beams for use with BS 5950 and BS 449 standard (Fig. 1). It is noted that, for the all Elliptical Cellular beam models, infill plates were added at both ends of the beam conforming to the BS 5950 standard in order to avoid the concentrated stress and web-post buckling at supports.

Table 1. Sections and dimensions of Elliptical Cellular beams.

\begin{tabular}{lcccccccc}
\hline Sections & $\begin{array}{c}\mathbf{H} \\
(\mathrm{mm})\end{array}$ & $\begin{array}{c}\mathbf{d} \\
(\mathrm{mm})\end{array}$ & $\begin{array}{c}\mathbf{b}_{\mathbf{f}} \\
(\mathrm{mm})\end{array}$ & $\begin{array}{c}\mathbf{t}_{\mathbf{f}} \\
(\mathrm{mm})\end{array}$ & $\begin{array}{c}\mathbf{t}_{\mathbf{w}} \\
(\mathrm{mm})\end{array}$ & $\mathbf{e}(\mathrm{mm})$ & $\begin{array}{c}\mathbf{f} \\
(\mathrm{mm})\end{array}$ & $\mathbf{p}(\mathrm{mm})$ \\
\hline ECB150x50 & 150 & 100 & 50 & 7 & 5 & 52.47 & 41.37 & 108.00 \\
ECB225x75 & 225 & 150 & 75 & 7 & 5 & 78.71 & 62.15 & 162.00 \\
ECB297x99 & 297 & 198 & 99 & 7 & 4.5 & 103.89 & 82.04 & 213.84 \\
ECB300x100 & 300 & 150 & 100 & 8 & 5.5 & 104.94 & 82.87 & 162.00 \\
ECB300x200 & 300 & 200 & 200 & 12 & 8 & 104.94 & 86.60 & 216.00 \\
ECB375x125 & 375 & 250 & 125 & 9 & 6 & 131.18 & 103.58 & 270.00 \\
ECB450x150 & 450 & 300 & 150 & 9 & 6.5 & 157.41 & 124.32 & 324.00 \\
ECB447x149 & 447 & 298 & 149 & 8 & 5.5 & 156.37 & 123.47 & 321.84 \\
ECB525x175 & 525 & 350 & 175 & 11 & 7 & 183.65 & 145.02 & 378.00 \\
ECB594x199 & 594 & 396 & 199 & 11 & 7 & 207.79 & 164.08 & 427.68 \\
ECB600x200 & 600 & 400 & 200 & 13 & 8 & 209.89 & 165.74 & 432.00 \\
ECB750x200 & 750 & 500 & 200 & 16 & 10 & 262.36 & 207.17 & 540.00 \\
ECB882x300 & 882 & 588 & 300 & 20 & 12 & 308.53 & 243.63 & 635.04 \\
ECB900x200 & 900 & 600 & 200 & 17 & 11 & 314.83 & 248.60 & 972.00 \\
ECB1350x300 & 1350 & 900 & 300 & 28 & 16 & 472.24 & 372.90 & 972.00 \\
\hline
\end{tabular}

Remark: $e=$ half-height of the elliptical opening, $f=$ half-width of the elliptical opening. 


\section{Result and Discussion}

The results of finite element analysis in lateral torsional buckling moment capacity of the Elliptical Cellular beams have been directly compared with the calculation following the equation of AISC 360-10 standard by using the sectional properties at web-post section as seen in Table 2 and Fig. 7. The example results in the table show that the moment capacity calculation following AISC standard is remarkably unconservative. The cause of this unsafe results came from the usages of the only three sectional properties, themoment of inertia about minor axis, $I_{y}$, torsional constant, $J$, and warping constant, $C_{w}$.

All of the lateral torsional buckling moment capacity results are plotted to present the relationship between $M / M_{F E A}$ and the modified slenderness, $\sqrt{M_{y} / M_{o c r}}$, as shows in Fig. 8. The definition of parameters are as followings: $M$ is the lateral torsional buckling moment calculated by AISC standard, $M_{F E A}$ is the moment result from finite element analysis, $M_{o c r}$ is the critical buckling moment, and $M_{y}$ is the section yielding moment. The result data were widely scatter in the zone of plastic range, inelastic buckling range, and elastic buckling range, which the turning point of elastic buckling behavior to inelastic buckling behavior is about at 1.20 of the modified slenderness. The observation of result data shows that the lateral torsional buckling moment capacity of the beam having the opening at the web is reduced depending mainly on the modified slenderness, which includes the beam length. Furthermore, it is observed that the moment reduction is also depending on the slenderness of the top flange. As noticed in the failure configuration of lateral torsional buckling (Fig. 9), the top flange of the beam undergone the compression until it was buckled and deflected to the lateral direction. Therefore, the guideline to evaluate the lateral torsional buckling moment capacity of Elliptical Cellular beam is properly formulated by using the reduction factor, $R_{E C B}$, to reduce the moment capacity from the equation given in AISC standard with consideration of sectional properties at the web-post section. This reduction factor, $R_{E C B}$, has been developed from the curve fitting with linear multiplied regression including two essential variables, the modified slenderness, $\sqrt{M_{y} / M_{o c r}}$ and the top flange slenderness, $b / 2 t_{f}$.

In overall observation of finite element analysis results, it is found that the stiffness of the beams are linear in earliest stage of loading, elastic behavior of beams. But when the onset of lateral torsional buckling occur, one edge of the beam top flange will encounter compressive yielding, and tensile yielding in the other. Subsequently, the load will drop from the maximum point and the beam behavior enters into the inelastic range, while the stiffness of beam was greatly reduced resulting from lateral displacement of the top flange, downward displacement and twist angle of the section.

The example of finite element analysis results on structural beam behavior are plotted in loaddeflection graph as shown in Fig. 10 for comparison the plain web and Elliptical Cellular beams. The directional deflections at mid-span are particularly separated into vertical and horizontal direction. The results show that the beams size of ECB150x50x1429 and ECB450x150x4288, which the lengths are in the inelastic buckling range, have displacement at mid-span length moving to the lateral direction as same as to the downward direction. This occurrence shows the inelastic buckling behavior with including the effect of little initial deformation. Whereas the beam size of ECB450x150x1696, which is in plastic range, the range that lateral torsional buckling does not apply, has the displacement hardly moving to the lateral side. Such behavior effect the beam strength encounter the full yielding of section mainly and directly affect to more difference of beam capacity while the Elliptical openings being present (as seen in Fig. 10(c)). The lateral deflection is found to be relatively small for the beam having low slenderness section, such as the beam ECB300x200x2955, which almost does not deflect laterally at the ultimate loading. The observation on stiffness of the beams also shows that there is almost no difference for the case of the plain web comparing with the Elliptical Cellular beams for the elastic behavior, but somewhat difference for the plastic behavior. 
Table 2. Example results of finite element analysis compare with AISC 360-10 standard.

\begin{tabular}{|c|c|c|c|c|c|c|c|}
\hline \multirow[t]{2}{*}{ Sections } & \multirow{2}{*}{$\begin{array}{c}\mathbf{L} \\
(\mathrm{mm}) \\
\end{array}$} & \multicolumn{4}{|c|}{ AISC (consider at web-post section) } & \multirow{2}{*}{$\begin{array}{c}\text { FEA } \\
(\mathrm{kN}-\mathrm{m})\end{array}$} & \multirow{2}{*}{$\begin{array}{c}\text { Reduction } \\
(\%) \\
\end{array}$} \\
\hline & & $\begin{array}{c}\mathbf{I}_{\mathbf{y}} \\
\left(\mathrm{mm}^{4}\right)\end{array}$ & $\underset{\left(\mathrm{mm}^{4}\right)}{\mathbf{J}}$ & $\begin{array}{c}\mathbf{C}_{\mathbf{w}} \\
\left(\mathrm{mm}^{6}\right)\end{array}$ & $\begin{array}{c}\mathbf{M} \\
(\mathrm{kN}-\mathrm{m})\end{array}$ & & \\
\hline ECB150x50 & 565 & $1.47 \times 10^{5}$ & 17079 & $7.53 \times 10^{8}$ & $18.04^{*}$ & 15.76 & 12.64 \\
\hline ECB150x50 & 997 & & & & $15.92 *$ & 14.44 & 9.31 \\
\hline ECB150x50 & 1429 & & & & $13.81 *$ & 13.05 & 5.49 \\
\hline ECB150x50 & 1861 & & & & $11.69 *$ & 10.56 & 9.64 \\
\hline ECB150x50 & 2294 & & & & 9.38 & 8.79 & 6.32 \\
\hline ECB150x50 & 2726 & & & & 7.69 & 7.20 & 6.36 \\
\hline ECB150x50 & 3158 & & & & 6.52 & 6.11 & 6.26 \\
\hline ECB150x50 & 3590 & & & & 5.67 & 5.32 & 6.19 \\
\hline ECB450x150 & 1696 & $5.07 \times 10^{6}$ & $1.12 \times 10^{5}$ & $2.47 \times 10^{11}$ & $218.83^{*}$ & 190.90 & 12.76 \\
\hline ECB450x150 & 2992 & & & & $178.14 *$ & 167.92 & 5.74 \\
\hline ECB450x150 & 4288 & & & & $137.45^{*}$ & 133.90 & 2.59 \\
\hline ECB450x150 & 5584 & & & & 88.19 & 87.51 & 0.77 \\
\hline ECB450x150 & 6881 & & & & 63.22 & 62.43 & 1.25 \\
\hline ECB450x150 & 8177 & & & & 48.81 & 47.95 & 1.76 \\
\hline ECB450x150 & 9473 & & & & 39.60 & 38.73 & 2.19 \\
\hline ECB450x150 & 10769 & & & & 33.28 & 32.44 & 2.54 \\
\hline ECB300x200 & 1168 & $1.60 \times 10^{7}$ & $2.78 \times 10^{5}$ & $3.32 \times 10^{11}$ & $210.89 * *$ & 198.42 & 5.91 \\
\hline ECB300x200 & 2955 & & & & $202.35^{*}$ & 193.31 & 4.47 \\
\hline ECB300x200 & 4743 & & & & $175.81 *$ & 180.58 & 3.53 \\
\hline ECB300x200 & 6530 & & & & $149.28^{*}$ & 154.30 & 3.22 \\
\hline ECB300x200 & 8318 & & & & 118.57 & 116.59 & 1.67 \\
\hline ECB300x200 & 10106 & & & & 92.63 & 91.13 & 1.62 \\
\hline ECB300x200 & 11893 & & & & 76.15 & 75.01 & 1.49 \\
\hline ECB300x200 & 13681 & & & & 64.74 & 63.86 & 1.36 \\
\hline ECB600x200 & 2261 & $1.74 \times 10^{7}$ & $3.91 \times 10^{5}$ & $1.50 \times 10^{12}$ & $537.16^{*}$ & 474.71 & 11.63 \\
\hline ECB $600 \times 200$ & 3989 & & & & $441.60 *$ & 403.52 & 8.62 \\
\hline ECB $600 \times 200$ & 5717 & & & & $346.04 *$ & 332.80 & 3.83 \\
\hline ECB600x200 & 7445 & & & & 226.75 & 222.94 & 1.68 \\
\hline ECB600x200 & 9173 & & & & 162.74 & 159.75 & 1.84 \\
\hline ECB600x200 & 10901 & & & & 125.73 & 123.12 & 2.07 \\
\hline ECB $600 \times 200$ & 12629 & & & & 102.08 & 99.78 & 2.25 \\
\hline ECB $600 \times 200$ & 14357 & & & & 85.84 & 83.79 & 2.39 \\
\hline ECB900x200 & 2094 & $1.92 \times 10^{9}$ & $1.04 \times 10^{6}$ & $4.44 \times 10^{12}$ & $1232.30^{*}$ & 1050.00 & 14.79 \\
\hline ECB900x200 & 3391 & & & & $1046.44^{*}$ & 935.56 & 10.60 \\
\hline ECB900x200 & 4686 & & & & $860.63 *$ & 814.68 & 5.34 \\
\hline ECB900x200 & 5983 & & & & 637.76 & 613.03 & 3.88 \\
\hline ECB900x200 & 8575 & & & & 348.48 & 338.30 & 2.92 \\
\hline ECB900x200 & 11167 & & & & 232.44 & 224.76 & 3.30 \\
\hline ECB900x200 & 13759 & & & & 172.96 & 166.43 & 3.78 \\
\hline ECB900x200 & 16351 & & & & 137.54 & 131.81 & 4.17 \\
\hline ECB900x200 & 18943 & & & & 114.24 & 109.16 & 4.45 \\
\hline ECB900x200 & 21535 & & & & 97.79 & 93.25 & 4.65 \\
\hline
\end{tabular}

* Lateral torsional buckling moment in inelastic range.

**Plastic moment in plastic range. 


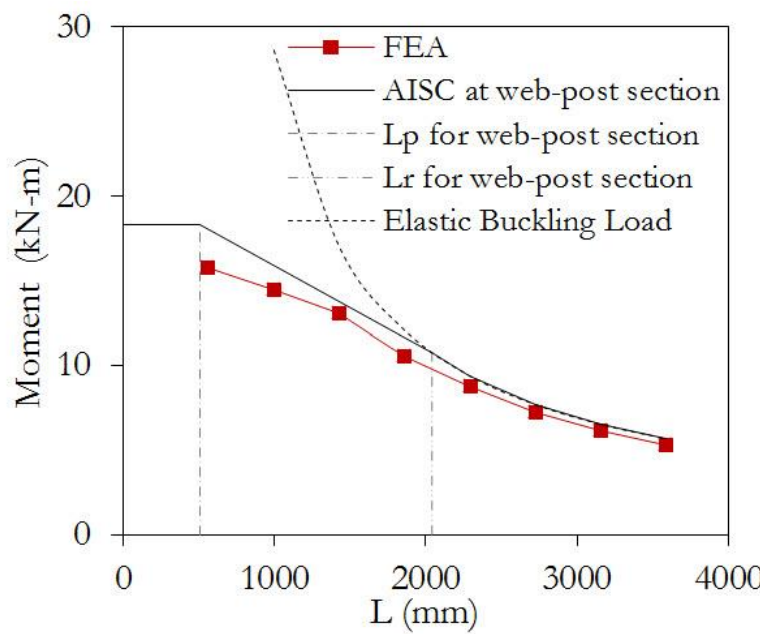

(a)

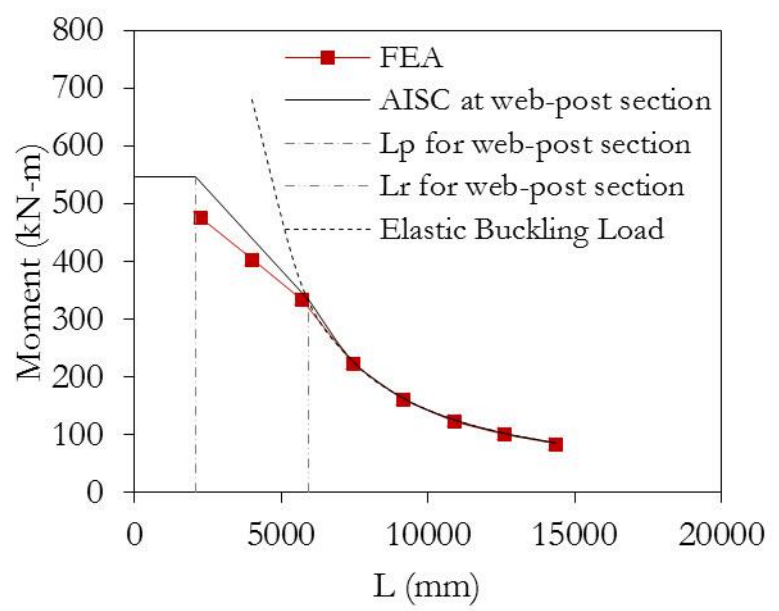

(c)

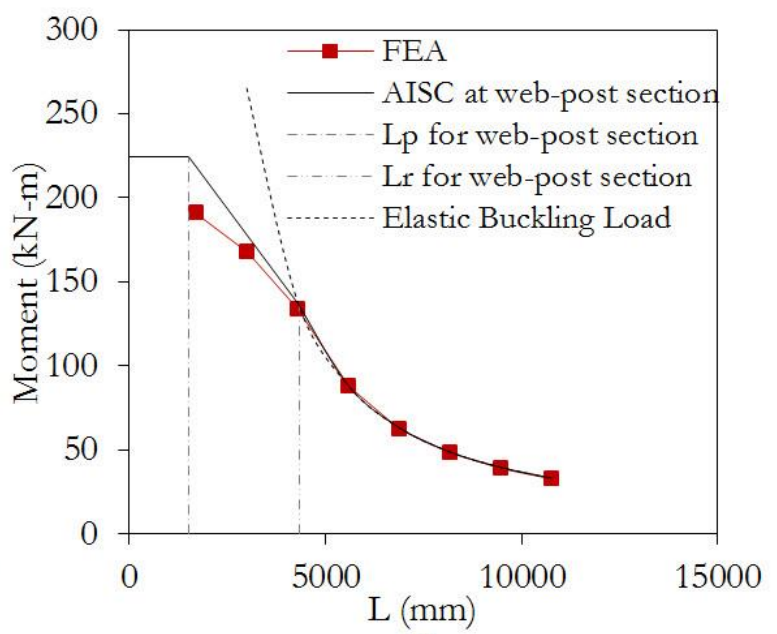

(b)

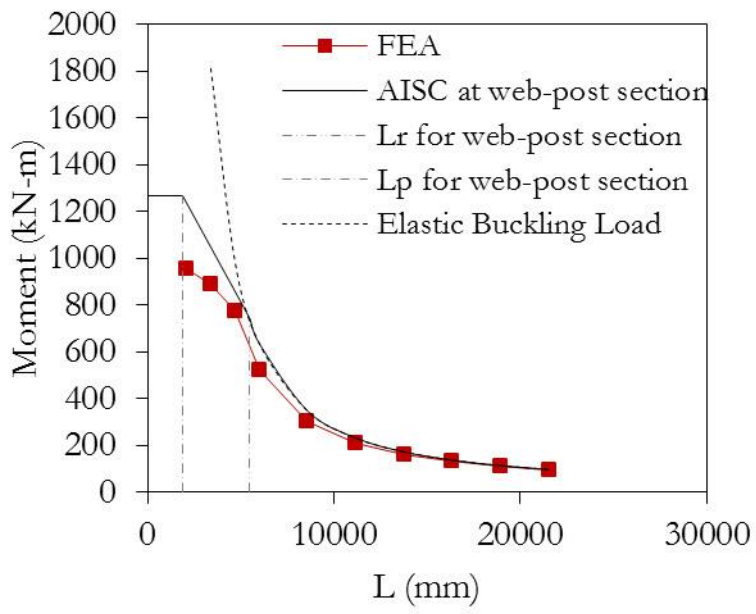

(d)

Fig. 7. Results of finite element analysis: (a) ECB150x50, (b) ECB450x150, (c) ECB600x200, (d) ECB900x200

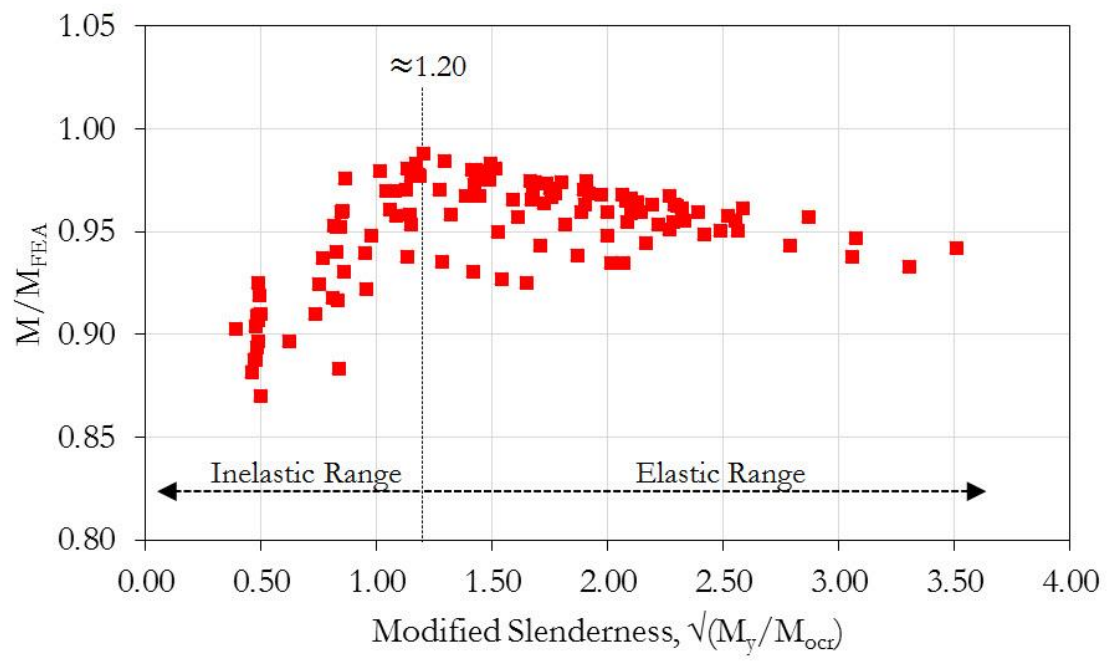

Fig. 8. Graph of reduction factor against modified slenderness with various flange slenderness. 


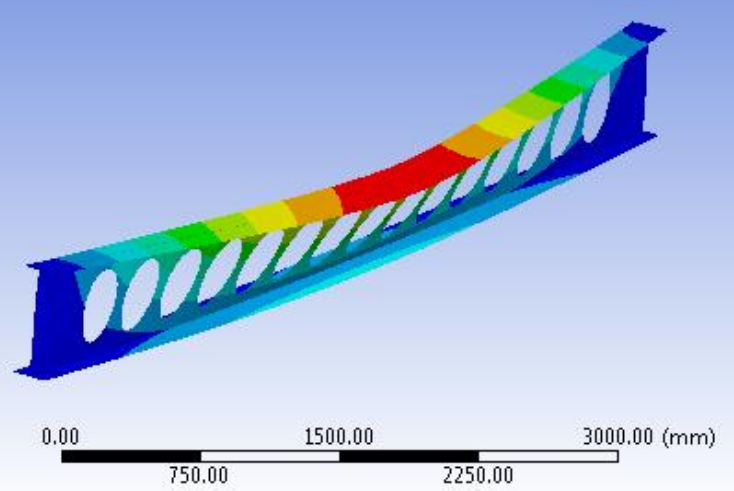

Fig. 9. Result of finite element analysis in lateral torsional buckling of Elliptical Cellular beam.

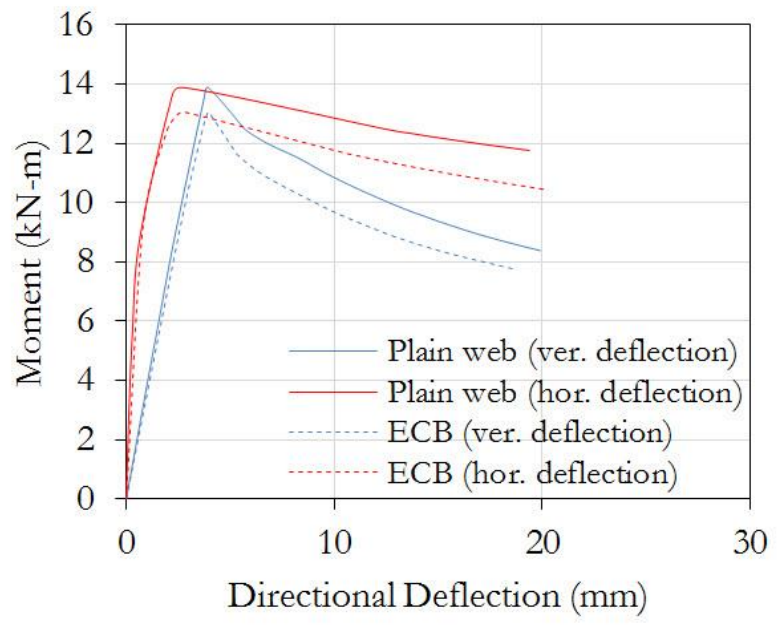

(a)

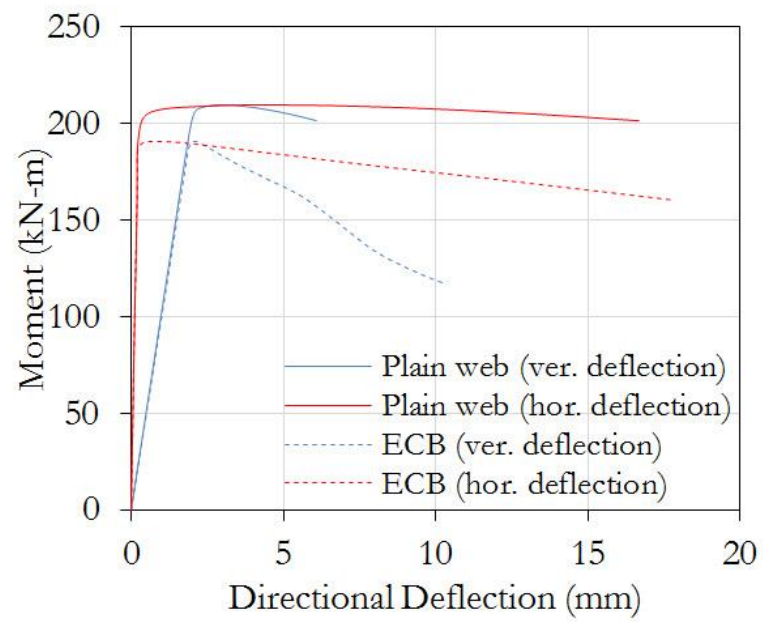

(c)

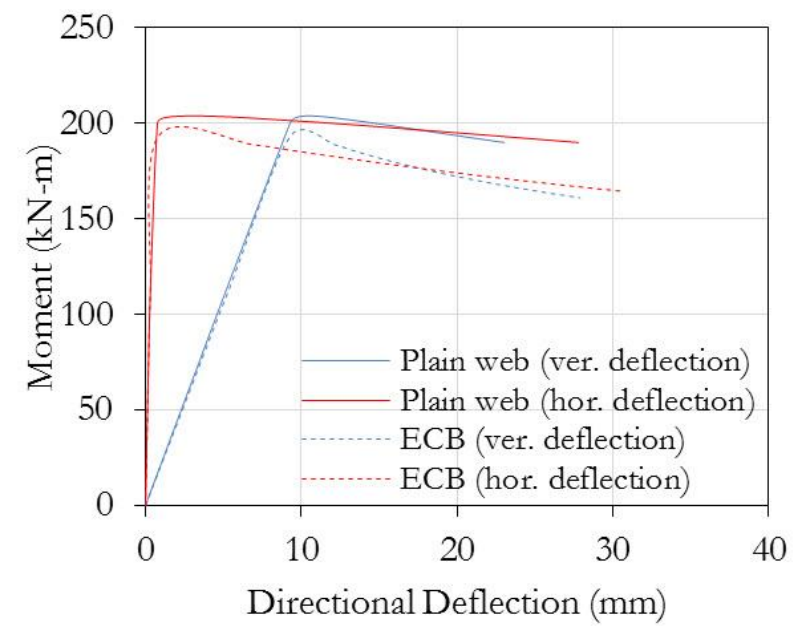

(b)

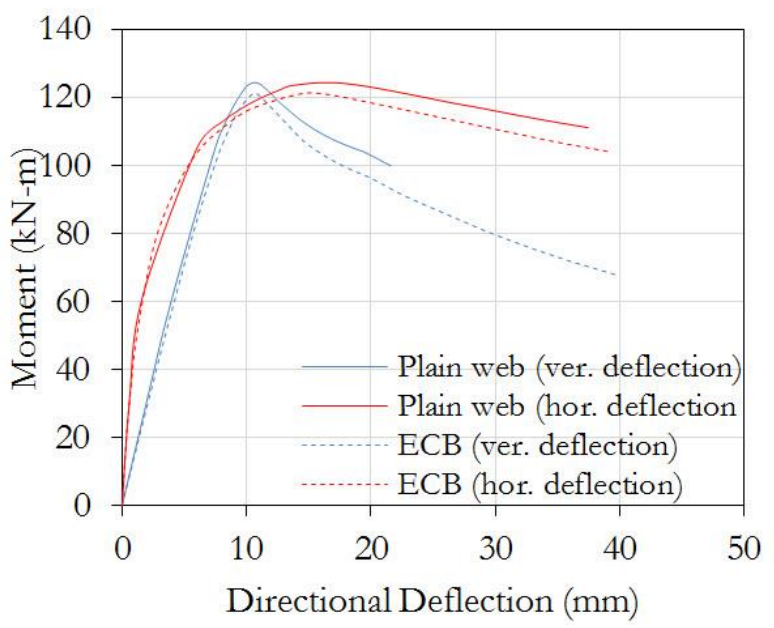

(d)

(a) ECB150x50x1429, (b) ECB300x200x2955, (c)

Fig. 10. Load-deflection comparison graph: ECB450x150x1696, and (d) ECB450x150x4288. 


\section{Coefficient Function for Evaluate Lateral Torsional Buckling Moment of Elliptical Cellular Beams}

As described in the earlier section that the equations to account for the lateral torsional buckling capacity used for the general steel beam are improper to represent the behavior for the Elliptical Cellular beam. Furthermore, using sectional properties at the web-opening section to design the Elliptical Cellular beam is unfairly conservative. Therefore, it is one of the main objectives for this paper is to propose applicable equation that developed from coefficient function obtained from the parametric study of the nonlinear buckling finite element analysis for more precise evaluation of the beam capacity. The proposed concept is to reduce the moment capacity from the standard equations using the sectional properties at the web-post section with a reduction factor, $R_{E C B}$. The scheme of the proposed concept has been plotted as shown in Fig. 11. The equations are illustrated in three ranges. The Elliptical Cellular beam that buckle in elastic range, the lateral torsional buckling moment capacity can be evaluated by using Eq. (5) that has a proposed reduction factor, $R_{E C B}$. This reduction factor is provided by empirical formula based on finite element results that the formula is depending on the sectional yielding moment at the web-post section, $M_{y}$, the critical lateral torsional buckling moment at the web-post section, $M_{\text {ocr }}$, and the slenderness of the top flange element, $b / 2 t_{f}$. For the inelastic range, Eq. (4) is developed based on the interpolation between the plastic moment at $L_{p}$ and the elastic moment at $L_{r}$ with the use of the reduction factor. Where in the equation, $M_{p, \text { hole }}$ is the plastic moment at the web-opening section, $C_{b}$ is the lateral torsional buckling modification factor for nonuniform moment diagrams, $I_{y}$ is the moment of inertia about minor axis, $J$ is the torsional rigidity, $C_{w}$ is the warping constant, $S_{x}$ is the elastic section modulus taken about the x-axis, $L_{b}$ is the length between lateral supports, $L_{p}$ is the limiting length between plastic and inelastic behavior, $L_{r}$ is the limiting length between inelastic and elastic behavior, $F_{y}$ is yield stress of material, $G$ is the shear modulus of elasticity, and $E$ is the Young's modulus of elasticity. For the plastic range, the evaluation of Elliptical Cellular beam is necessary to use Eq. (3) that consider the sectional properties at the web-opening section because the beam will not undergo into the buckling behavior that affect the beam failure by fully yielding at web-opening section. It is noted that, for the elastic range, the main reason accounting for sectional properties at the web-post section is to simplifier the evaluation, the calculations of $I_{y}, J$ and $C_{w}$.

In plastic length:

$$
M_{n}=M_{p, h o l e}
$$

In inelastic length:

$$
M_{n}=C_{b}\left[M_{p, \text { hole }}-\left(M_{p, \text { hole }}-0.7 \cdot R_{E C B} \cdot F_{y} S_{x}\right)\left(\frac{L_{b}-L_{p}}{L_{r}-L_{p}}\right)\right] \leq M_{p, \text { hole }}
$$

In elastic length:

$$
M_{n}=R_{E C B} \cdot M_{c r}=R_{E C B} \cdot C_{b} \frac{\pi}{L_{b}} \sqrt{E I_{y} G J+\left(\frac{\pi E}{L_{b}}\right)^{2} I_{y} C_{w}}
$$

where

$$
R_{E C B}=0.9429-0.0135 \sqrt{\frac{M_{y}}{M_{o c r}}}+0.0063\left(\frac{b}{2 t_{f}}\right)
$$




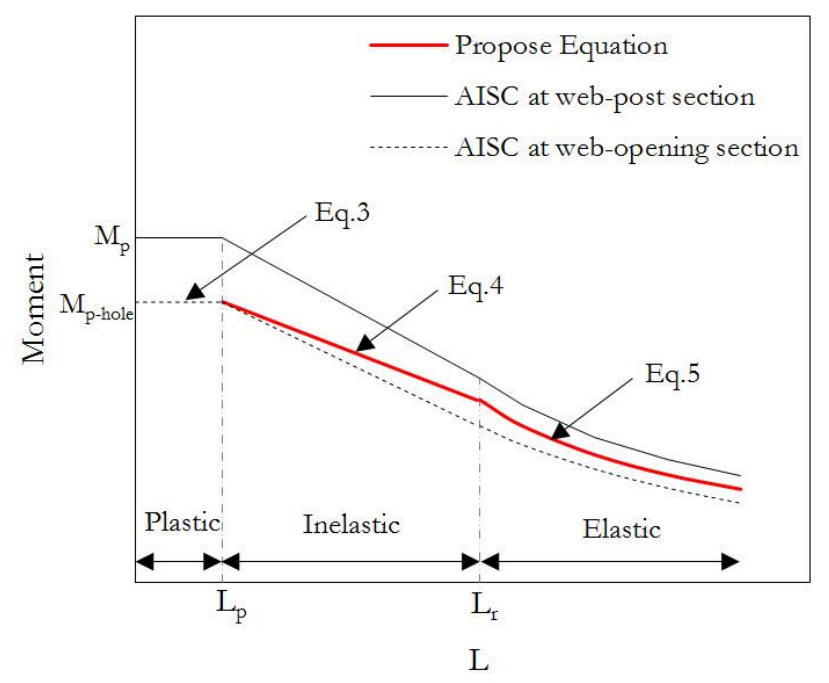

Fig. 11. Schematic plot for evaluating lateral torsional moment of Elliptical Cellular beam.

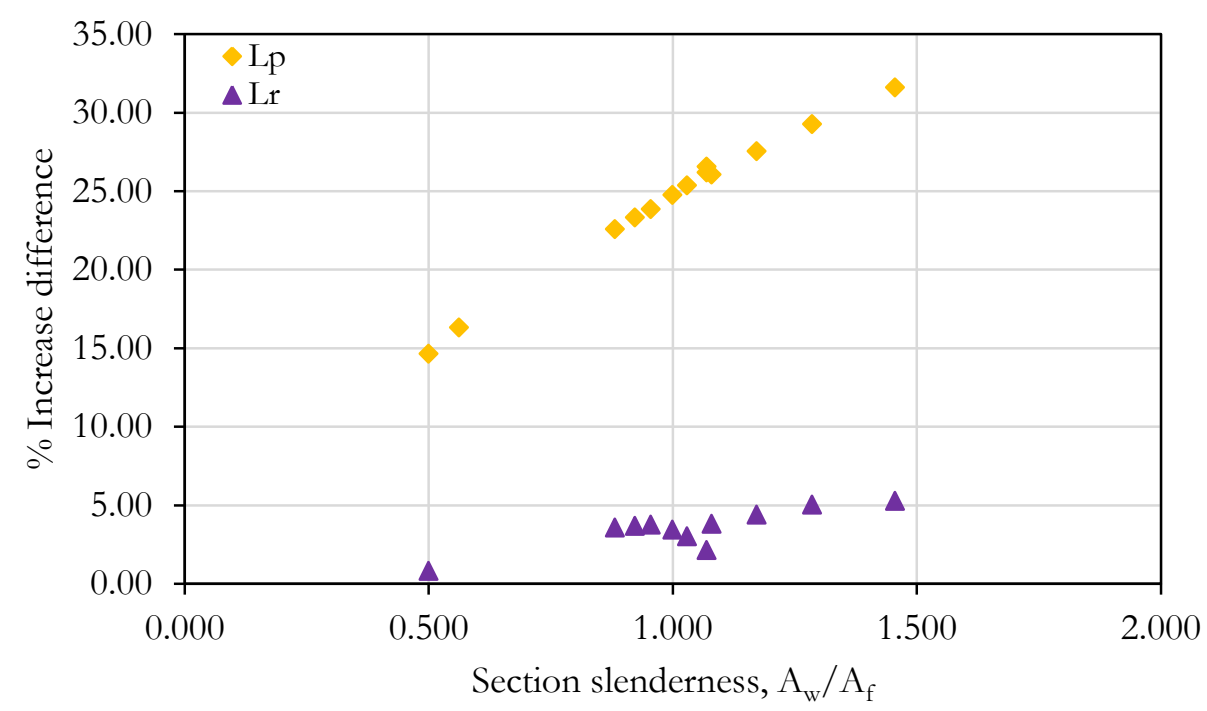

Fig. 12. Difference when considering the sectional properties at web-post section and at web-opening section that effect the increasing values of $L_{p}$ and $L_{r}$.

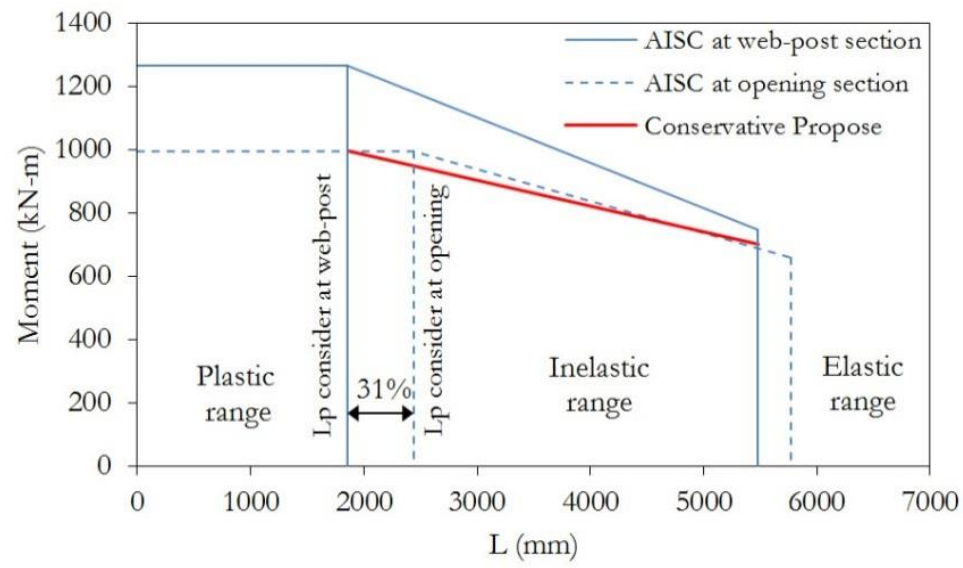

Fig. 13. Conservative propose for $L_{p}$ (example results of ECB900x200 specimen). 
In consideration the values of $L_{p}$ and $L_{r}$, the results of the study show that there are negligible difference of $L_{r}$ between consideration the sectional properties at the web-post section and at the webopening section. The difference is about 5 percentage when comparing the section slenderness, $A_{w} / A_{f}$, as shown in Fig. 12. However, in the consideration of $L_{p}$, it is found that there are noticeable difference of approximately 15 percentage to up to 35 percentage with the variation of the section slenderness, $A_{w} / A_{f}$. Fig. 13 is plotted to further demonstrate in detail of an example case, ECB900x200, which is the case of the extreme $L_{p}$ difference. It is observed that using the sectional properties at the web-post section is convenient and yield slightly conservative results. Therefore, in the procedure of calculation, it is also appropriate to propose to use the sectional properties to determine $L_{p}$ and $L_{r}$ at the web-post section.

The results of the proposed procedure in evaluation the lateral torsional buckling moment capacity of Elliptical Cellular beams are compared with the results of the calculation conformed to the AISC standard with both considering sectional properties at the web-post section and at the web-opening section (as seen in Fig. 14). The comparison shows that the results of AISC Standard eqution using sectional properties at the web-post section obviously give unconservative results. The unconservative result is about 5 percent in elastic buckling range and when the beam lengths are in inelastic buckling range, the unconservative can increasingly be up to 20 percent with the increasing effect in the plastic range. Considering AISC equation using sectional properties at the web-opening section, it can be found that the results are always below the conservative line for up to 10 percent. The use of sectional properties at the web-opening section also shows the wide distributed ranges of the results. Finally, focusing on the results evaluated by using the reduction factor from this proposal, it is observed that the results have given reasonable conservative evaluation, more precision, and less distribution of the results than the two previous calculation methods.

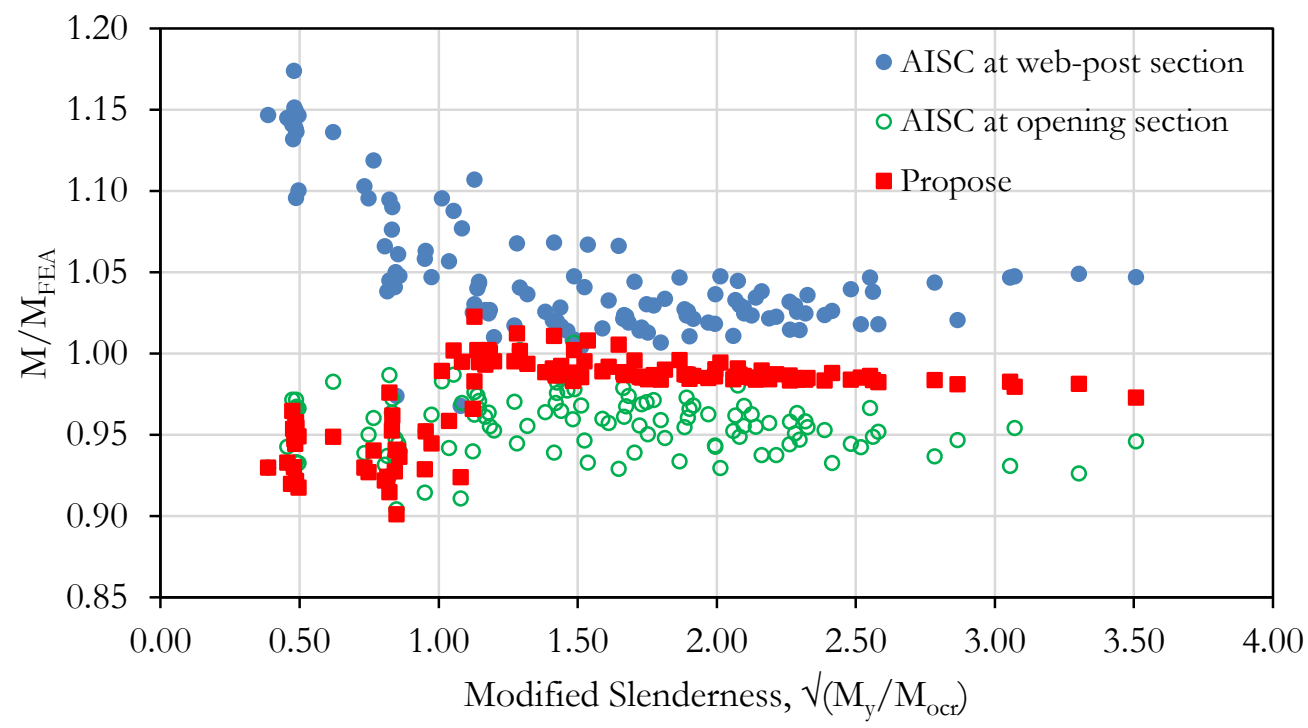

Fig. 14. Result of the comparison of lateral torsional buckling moment evaluation of Elliptical Cellular beam. 


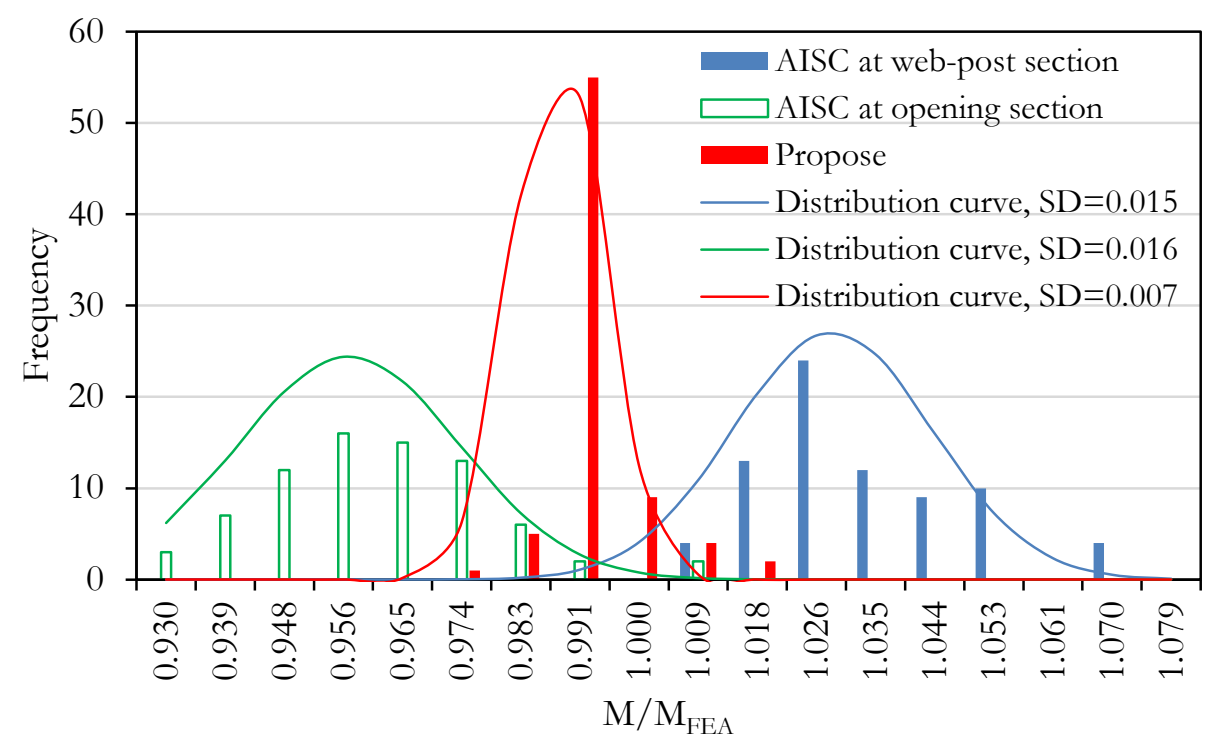

Fig. 15. Probability distribution graph of moment capacity evaluation.

Furthermore, considering statistics analysis, the probability distribution of all data in elastic buckling range is plotted in Fig. 15. The calculation of lateral torsional buckling moment of Elliptical Cellular beams that follow the AISC standard with the use of sectional properties at the web-post section yields the results with the arithmetic mean of 1.03 and the distribution in standard deviation (S.D.) of 0.0147. The calculation with the use of sectional properties at the web-post section gives the arithmetic mean of 0.96 and the standard deviation of 0.0163 . Lastly, the evaluation using of the reduction factor, $R_{E C B}$, concept from this proposal provides precise results with the arithmetic mean of 0.99 and the less distribution of results with the standard deviation of 0.0068 .

In addition, from the study of the lateral torsional buckling moment of Elliptical Cellular beams in other load cases, it is found that the presence of elliptical openings along the beam web has no effect directly to the lateral torsional buckling moment, especially, in elastic buckling behavior range. But in the inelastic and plastic range, it was found that some of the beam models had encoutnered another failure modes such as web-post buckling, web-post shear failure in the region of high shear force, or Vierendeel mechanism failure, similarly to the previous study by P. Panedpojaman, W. Sae-Long and T. Chubuppakarn [23]. Likewise the use of the method to reduce the moment gradient factor, $C_{b}$, in the inelastic range for other load cases recommended by A. Mohebkhah [15].

\section{Conclusion}

The linear and nonlinear buckling analysis by using finite element method have been performed in this study to investigate the lateral torsional buckling moment capacity of Elliptical Cellular beams in both elastic and inelastic buckling range. The main essences of this study can be concluded as followings:

1. In the evaluation of the lateral torsional buckling moment of Elliptical Cellular beams, by considering section properties at the web-post section, the equation given in AISC standard is obviously unsafe. The results of this unconservative design comparing to the finite element analysis show that the unconservative is about 5 percent in elastic range, and significantly up to 20 percent in inelastic and plastic range.

2. The lateral torsional buckling moment of Elliptical Cellular beams can be conservatively design by using the reduction factor from this proposal, $R_{E C B}$. The results using the proposed reduction factor $\left(R_{E C B}\right)$ to evaluate the lateral torsional buckling moment capacity show appropriate and precise results for design with more accuracy, more economical and less distribution of results.

3. The accounting for sectional properties at the web-post section and the web-opening section of Elliptical Cellular beams yield negligible difference in the value of $L_{r}$. However, for the value of $L_{p}$, it can be different for up to 31 percent. It is slightly more conservative to calculate the value of $L_{p}$ by 
using sectional properties at the web-post section. Therefore, this study propose to use sectional properties of Elliptical Cellular beams at the web-post section in both $L_{p}$ and $L_{r}$.

\section{References}

[1] P. R. Knowles, Design of castellated beams for use with BS 5950 and BS 449, Steel Construction Institute, Constrado, United States, 1985.

[2] K. F. Chung and T. C. H. Liu, "Steel beams with large web openings of various shapes and sizes: Finite element investigation," Journal of Constructional Steel Research, vol. 59, pp. 1159-1176, Feb. 2003.

[3] K. F. Chung, C. H. Liu, and A. C. H. Ko, "Steel beams with large web openings of various shapes and sizes: An empirical design method using a generalized moment-shear interaction curve," Joumal of Constructional Steel Research, vol. 59, pp. 1177-1200, Feb. 2003.

[4] K. D. Tsavdaridis and C. D'Mello, "FE investigation of perforated sections with standard and nonstandard web opening configurations and sizes," presented at The 6th International Conference on Advances is Steel Structures, Hong Kong, China, 2009.

[5] K. D. Tsavdaridis and C. D'Mello, "Web buckling study of the behavior and strength of perforated steel beams with different novel web opening shapes," Journal of Constructional Steel Research, vol. 67, pp. 1605-1620, May 2011.

[6] K. D. Tsavdaridis and C. D'Mello, "Optimisation of novel elliptically-based web opening shapes of perforated steel beams," Journal of Constructional Steel Research, vol. 76, pp. 39-53, May. 2012.

[7] P. Limtrakul and K. Phuvoravan, "Effect of opening width and opening angle to the flexural strength of the castellated beam," in $19^{\text {th }}$ National Convention on Civil Engineering, Khon Kaen, Thailand, May 1416, 2014, pp. 175-181.

[8] E. Ellobody, "Interaction of buckling modes in castellated steel beams," Journal of Constructional Steel Research, vol. 67, pp. 814-825, 2011.

[9] E. Ellobody, "Nonlinear analysis of cellular steel beams under combined buckling modes," ThinWalled Structures, vol. 52, pp. 66-79, 2012.

[10] P. Panedpojaman and T. Thepchatri, "Finite element investigation on deflection of cellular beams with various configurations," International Journal of Steel Structures, vol. 13, no. 3, pp. 487-494, Sept. 2013.

[11] D. Sonck, "Global buckling of castellated and cellular beams and columns," Ph.D. dissertation, Ghent University, Belgium, 2014.

[12] P. Ponsorn and K. Phuvoravan, "Study of finite element analysis type to the nonlinear buckling behavior of cellular beams," in The 53th Kasetsart University Annual Conference, Vajiranusorn Building, Faculty of Agriculture, Kasetsart University, Bangkok, Thailand, 2015.

[13] AISC, Specification for Structure Steel Buildings (ANSI/AISC 360-10), Chicago, Illinois. American Institute of Steel Construction, June 22, 2010.

[14] D. E. Kerdal, "Lateral-torsional buckling strength of castellated beams," Ph.D. dissertation, University of Sheffield, South Yorkshire, England, 1982.

[15] A. Mohebkhah, "The moment-gradient factor in lateral torsional buckling on inelastic castellated beams," Journal of Constructional Steel Research, 60, pp. 1481-1494, Feb. 2004.

[16] A. Mohebkhah and H. Showkati, "Bracing requirements for inelastic castellated beams," Journal of Constructional Steel Research, vol. 61, pp. 1373-1386, Mar. 2005.

[17] H. Showkati, T. G. Ghazijahani, A. Noori, and T. Zirakian, "Experiments on elastically braced castellated beams," Journal of Constructional Steel Research, vol. 77, pp. 163-172, Jun. 2012.

[18] A. M. I. Sweedan, "Elastic lateral stability of I-shaped cellular steel beams," Journal of Constructional Steel Research, vol. 67, pp. 151-163, Aug. 2010.

[19] P. Ponsorn, "Lateral torsional buckling behavior of elliptical cellular steel beams with various sections and lengths," M.S. Thesis, Department of Civil Engineering, Faculty of Engineering, Kasetsart University, Bangkok, Thailand, 2015.

[20] S. A. Ibrahim, A. K. Dessouki, and S. A. EI -Sa'eed, "Lateral buckling behavior and strengthening techniques of coped steel I-beams," Journal of Constructional Steel Research, vol. 108, pp. 11-22, Febuary 21, 2015. 
[21] J. Nseir, M. Lo, D. Sonck, H. Somja, O. Vassart, and N. Boissonnade, "Lateral torsional buckling of cellular steel beams," in Proceedings of the Annual Stability Conference Structural Stability Research Council, Grapevine, Texas, April 18-21, 2012.

[22] D. Sonck and J. Belis, "Lateral-torsional buckling resistance of cellular beams," Journal of Constructional Steel Research, vol. 105, pp. 119-128, Nov. 2014.

[23] P. Panedpojaman, W. Sae-Long, and T. Chub-uppakarn, "Cellular beam design for resistance to inelastic lateral-torsional buckling," Thin-W alled Structures, vol. 99, pp.182-194, 2016.

[24] ANSYS, ANSYS ver. 14.5.0 release Workbench Help. SAS IP, Inc. 2012. 